\title{
Discriminant analysis application to understand the usage of digital channels while buying a car
}

\author{
Rekha Dahiya \\ Faculty of Commerce and Management, SGT University, Gurugram, India, and \\ Dimpy Sachar \\ Management (Faculty), BCIPS, New Delhi, India
}

\section{Discriminant analysis application}

\begin{abstract}
Purpose - Role of digital channels in car buying has increased manifold and consumers are making significant use of various digital channels throughout the decision-making process. However, there are very less number of studies available if one wishes to understand the specific reason(s) for the use of a particular digital channel of communication. This study deals with the identifications of the reason(s) leading towards the usage of particular digital channel of communication while buying a car.

Design/methodology/approach - Quantitative methodology was adopted for the study. A total of 10 digital channels namely the websites, social networking sites, YouTube, Smartphones, Online communities, Digital TV, Digital Outdoors, e-mails and others were considered in the study. Data was collected from 603 car buyers from Delhi using digital channels of communication.

Findings - The results of the study revealed that Website and YouTube were used for being compatible. Social networking sites, smartphones, digital outdoors and e-mails were used for being informative. Online communities were used for offering customers and experts' reviews. Digital TV was used for being easy to use. Research limitations/implications - The study considers the respondents from Delhi only. A more representative sample covering various parts of the country would offer more relevant results for the marketers as digital divide existing between rural and urban India cannot be simply ignored.

Practical implications - The study reveals that car buyers are making ample usage of digital channels wherein website is the most used digital channel and smartphones are the most used digital devices used by the car buyers.

Social implications - Study also reveals that car buyers might use search engines to reach the marketer's website, so effective search engine optimization (SEO) strategies should be adopted. Important keywords used in the search engines should be used in the website as well as in the links.

Originality/value - Majority of the available studies use digital as an umbrella term for myriad digital channels. So understanding about the usage of specific channel of communication remains an under-researched area. Such understanding strengths and broadens the existing knowledge about technology mediated consumer behaviour especially in extended problem-solving product category.
\end{abstract}

Keywords Digital marketing, Indian car market, Digital channels, Discriminant analysis

Paper type Research paper

\section{Introduction}

Always connected customers are ushering the paradigm changes in the marketers' strategies by warranting an unparalleled customer experience throughout their purchase journey. Marketers too are embracing digital technologies not just to fuel in the efficiency in their existing operations, but also to acknowledge and adapt the changes in consumer behaviour

(C) Rekha Dahiya and Dimpy Sachar. Published in South Asian Journal of Marketing. Published by Emerald Publishing Limited. This article is published under the Creative Commons Attribution (CC BY 4.0) licence. Anyone may reproduce, distribute, translate and create derivative works of this article (for both commercial and non-commercial purposes), subject to full attribution to the original publication and authors. The full terms of this licence may be seen at http://creativecommons.org/licences/by/4.0/ legalcode

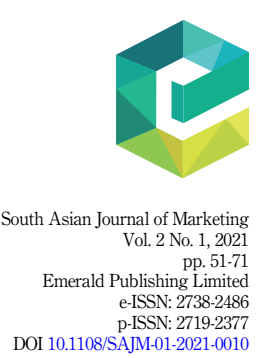

Received 25 January 2021

Revised 16 March 2021

10 April 2021

14 April 2021

Accepted 3 May 2021 
SAJM

2,1

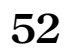

(Lund, 2020). IDC study (2018) claims that more than two-third of the top 2000 global marketers are already using digital technologies to serve, engage and delight their customers with an increasing spending towards digital platforms. Marketers are using digital channels of communication owing to several features such as being interactive, customized, measurable, informative, relevant and cost effective. The apparent benefits of digital media accredit latter an effective communication alternative medium over its traditional counterpart.

Digital channels enable marketers to offer a consistent omni-channel experience to its customers that they always wished for (Lezmi, 2020). Accenture study indicates that customers' frustration due to inconsistent experience over different channels of communication (Kulbyte, 2020). Lezmi (2020) claims that usage of digital channels helps companies offer consistent customer experience leading towards the retention of $89 \%$ of its customers. Excellent customer satisfaction, augmented customer engagement and matchless customer experience are the key benefits of deploying digital technologies in business for marketers (Lund, 2020). Customer engagement results in enhanced probability of trying new products of the company and recommending products or brands to the friends ultimately leading towards increased customer loyalty. Rosetta Consulting (2014) asserts that customer engagement also results in increased market share as highly engaged customers buy $90 \%$ more frequently and three times of average customers. As per the research of MIT (2013), companies focusing upon digital customer experience and engagement tend to be $26 \%$ more profitable than others.

Wertime and Fenwick (2011) in their study listed various modern digital marketing channels used by the marketers namely the websites, social networking sites, YouTube, online communities, e-mails, mobile phones, digital TV and digital outdoors. A company's website is a significant communication tool between a marketer and its customers and lies at the heart of digital marketing (Stokes, 2013). Website is normally the first among the digital channels that potential customers use to explore the information about the marketer. Social media has transformed the communication process between marketers and consumers due to its inherent capabilities, i.e. to interact, engage and building intimate customer relationships (Hanna et al., 2011).

Online communities also known as "message boards" or "Internet forums" refer to webenabled and supported discussion sites where-by users can converse with one another in the form of posted messages (Armstrong and Hagel, 2000). Consumers exhibit lot of faith in the online communities as members appreciate the experience of other community members. Online communities' provide a convenient platform for like-minded people sharing common interest (Chen et al., 2004). Email acts as a great marketing tool for marketers for obvious reasons of precise targeting, easiness and cost-effectiveness (MacDonald, 2016). Moreover, key metrics like open, conversion, delivery rates and clicks are easy to measure with the help of special tracking software available in the market like "Google Analytics URL builder" (Chaffey, 2016).

Mobile phones have created a kind of "third revolution" after the industrial and agricultural revolution (Singh, 2014). Interactivity, measurability, localization and ubiquity of mobile phones are responsible for its acceptance as modern day marketing tool among the customers (Manzoor, 2010). Digital TV also known as "interactive TV" offers numerous benefits to its users over its analogue counter-part by establishing a dialogue with its viewers (Rouse, 2009). Digital TV allows its users to access the desired information by entering menus. Viewers can respond to marketing offers promptly with the click of the remote, and marketers can direct viewers to other digital devices namely mobiles phones, tablets, desktop for further engagement (Poggi, 2012). Digital outdoors are the contemporary digital channels comprising of dynamic billboards and digital screens placed at strategic locations like restaurants, shopping malls, kiosks, bus stands, airports and railway stations (Fera, 2012).

Car marketers have also adopted digitalization in their core processes such as informing the customers, interacting and engaging the customers, promoting the brand, assisting the customers in evaluation, offering sales support to the customers and ensuring the 
post-purchase satisfaction. They are increasing their advertising spend towards digital platforms and applying automation technologies such as chat-bots, mobile apps, digital showrooms at retail front also. Car marketers are trying to build more meaningful relationships with their customers through digital channels by making their entire car buying process more pleasant, interesting and customized (Automotive Tech, 2019). They are shifting significant share of their marketing budget to digital platforms. Srivatsa (2020) posits that car marketers have shunned one-size-fits-all approach and have focused on interactivity and personalization.

Sharma (2018) claimed that over ₹13,000 crores were spent on various digital platforms by the Indian automobile players in the year 2018. Indian automobile players such as Tata and Hyundai have invested in digital initiatives like virtual showrooms, microsite of particular brand and usage of augmented and virtual reality to offer unique customer experience. A report by Dentsu Aegis Network suggests that automobile sector along with banking and insurance, e-commerce, FMCG and consumer durables is the leading contributor towards digital advertisement (Tewari, 2020). Digital channels have proved their worth for the marketers during Covid-19 pandemic outspread also wherein marketers have utilized these channels to stay relevant and connected with its customers. Car marketers though consider traditional promotional mix an important element in their overall communication plan, still they are very optimistic about digital platforms and aim to increase their advertising budget for digital channels (Nagar, 2020).

Car buyers no longer follow a stereotypical route to buy a car. They have become accustomed to omni-channel marketing strategy wherein they switch between offline and digital channels during their car purchasing journey. They are demanding a seamless customer experience. There is no doubt about the fact that role of digital channels in car buying has increased manifold and consumers are making significant use of various digital channels throughout the decision-making process (Cox Automotive Report, 2018). Car buyers want to take an informed decision by employing new age technologies. They are not indulging in any cross-dealership inquiry and also wish to save their time and efforts (Deloitte Global Automotive Study, 2019). A great majority of car buyers (i.e. between 70 and $80 \%$ ) use their smartphones not only to search about the vehicle but also about the dealer, negotiation, finance options and booking a test drive (V12, 2020).

Car buyers are looking for neutral and authentic opinion before buying the vehicle and resorting to third-party websites for the vehicle reviews (Digital Marketing Institute, 2020). Cox Automotive Report (2018) suggests that 70\% of car buyers put their trust primarily in third-party websites such as cardekho.com, carwale.om etc. to evaluate the vehicle followed by dealership websites used by $53 \%$ of car buyers and OEM websites referred by only $29 \%$ of the car buyers. Sharma (2018) claims that car buying journey has been interspersed with digital interventions wherein out of total 28 touch points in car buying journey, 21 are completed online. KPMG and Facebook Study (2018) claims that visit of a customer to dealers' showrooms has reduced from 5 to 2.2 times and $54 \%$ customers change their selected brand after searching online.

Digital intervention in automobile sector is well accepted wherein both marketers and consumers are using myriad digital channels. However, there are certain aspects of digital media which are under-studied that confine the level of efficiency and effectiveness of its usages such as distinguishing reasons accounting for the usage of distinct digital channels. This study aims to understand this under studied aspect of digital marketing communication's application in Indian passenger car market.

\section{Literature review}

Digital media has emerged as the frontrunner communication channel alterative for marketers across industries. The available literature demonstrates that digital channels of

Discriminant analysis application 
SAJM

2,1

\section{4}

communication have specific qualities such as being informative, interactive, relevant, compatible, cost-effective and easy to use that make digital media the preferred communication medium both for the consumers and marketers (Dahiya, 2013). Table 1 lists the salient features of digital media on the basis of reviewed literature.

Kaufman and Horton (2014) and Chaffey (2019) attributed digital channels highly informative whereby these channels offer unimaginable quantity of information to the customers almost instantly. Polanco-Diges and Debasa (2020) also appreciate the quick nature of digital channels wherein consumers acknowledge the real swift nature of digital technologies. Saura (2020) accredits interactivity dealing with ability of a medium to produce output as per user's input/needs; as one of the most prominent reasons for which consumers prefer digital channels of communication over the traditional communication channels (Saura, 2020). Dahiya and Gayatri (2018) in their study stressed that digital marketing offers entirely relevant content by enabling marketers to deliver real-time, personalized and individual content and services.

Digital channels give variety of the information to the consumers that involves information about products and services, others' opinion in the form of reviews and recommendations, comparative analysis and information about transaction and payment for goods and services to name a few (Key, 2017). Kannan (2017) asserts that digital channels have the capability to offer the information as desired by the consumers, i.e. to their preferred device, location and time. Compatibility refers to the ability of digital communication to deal and interact with the varied capabilities of different digital devices, browsers, operating systems and text formats through which consumers access the digital content (Chaffey, 2019). Contemporary digital channels have the capabilities to provide easy and quick access to digital content without altering the latter's configuration (Alghizzawi, 2019). Digital channels communication also offers customer and expert reviews that facilitate the product comparison and possibility of making an informed decision (Dahiya and Gayatri 2018; Gupta and Vohra, 2019) in their study confirmed that social media usage intensity positively and

\begin{tabular}{|c|c|c|}
\hline $\begin{array}{l}\text { Sr. } \\
\text { No }\end{array}$ & $\begin{array}{l}\text { Digital marketing } \\
\text { characteristics }\end{array}$ & Reference studies \\
\hline 1 & Informative & $\begin{array}{l}\text { Deloitte (2020), Tewari (2020), Chaffey (2019), Key (2017), Kaushik (2016), } \\
\text { Bhattacharya (2015), Mogensen (2015), Kaufman and Horton (2014), } \\
\text { Adikesavan (2014) }\end{array}$ \\
\hline 2 & Quick & $\begin{array}{l}\text { Polanco-Diges and Debasa (2020), Alghizzawi (2019), Kannan (2017), } \\
\text { Dahiya and Gayatri (2018), Capgemini (2015), C+R Research (2014) }\end{array}$ \\
\hline 3 & Interactive & $\begin{array}{l}\text { Saura (2020), Tewari (2020), Dahiya and Gayatri (2017), Chaffey and } \\
\text { Smith (2017), Durmaz and Efendioglu (2016), Edelman and Heller (2015), } \\
\text { Ioanăs and Stoica (2014) }\end{array}$ \\
\hline 4 & Relevant & $\begin{array}{l}\text { Mahalingam and Ashokkumar (2020), Chaffey (2019), Kannan (2017), } \\
\text { Capgemini (2015), Syme (2015), Kirkpatrick (2012), Jones et al. (2011) }\end{array}$ \\
\hline 5 & Easy & $\begin{array}{l}\text { Eze et al. (2020), Alghizzawi (2019), Chaffey and Smith (2017), Durmaz } \\
\text { and Efendioglu (2016), Charan and Dahiya (2015), Nguyen (2014) }\end{array}$ \\
\hline 6 & Expert Advice & $\begin{array}{l}\text { Parab (2020), Dahiya and Gayatri (2018); Chaffey and Smith (2017); } \\
\text { Charan and Dahiya (2015); Kusuma (2015); Bagchi (2013) }\end{array}$ \\
\hline 7 & Easy Comparison & $\begin{array}{l}\text { Digital Marketing Institute (2020), Alghizzawi (2019), Dahiya and } \\
\text { Gayatri (2018), Capgemini (2015), Nguyen (2014) }\end{array}$ \\
\hline 8 & Customer Reviews & $\begin{array}{l}\text { Deloitte (2020), Dahiya and Gayatri (2018), Chaffey and Smith (2017), } \\
\text { Charan and Dahiya (2015), Hausman (2014), Bagchi (2013) }\end{array}$ \\
\hline 9 & Compatibility & $\begin{array}{l}\text { Eze et al. (2020), Parab (2020), Chaffey (2019), Dahiya and Gayatri (2018), } \\
\text { Chaffey and Smith (2017), Wigmore (2013) }\end{array}$ \\
\hline \multicolumn{3}{|c|}{ Source(s): Literature review } \\
\hline
\end{tabular}

Table 1.

Reference studies used for construction of scales

Source(s): Literature review 
significantly influences three behavioural traits of consumers like materialism, impulse buying and conspicuous consumption.

Digital marketing has affected every facet of business, but communication has been the most affected area (Rekha and Jain, 2019). Digital interventions have affected every industry and Indian passenger car market is no exemption. A latest report by Deloitte (2020) states that digital channels such as websites, video sharing sites and social media have transformed the car buying process by turning to highly personalized experience for the car buyers thereby making it more relevant. The report while elaborating the consumer buying process posits that consumers initiate their search process either in response to the marketers' stimulus or on their own. Websites are playing a great role in solving their queries regarding the features, price, service warranty, finance schemes, etc. Car buyers are also making ample usage of their contemporary technologies such as augmented reality and virtual reality to have overall feel of the vehicle. Reviews available over social media are paid attentions by the potential car buyers whereby reviews are influencing the decisions of the car buyers.

Study conducted by Automotive Tech (2019) also corroborates well with Deloitte study (2020) whereby it states although digital channel affects all the stages of consumer buying decision process while buying car, still gathering information through digital channels especially the search engine websites are preferred more specifically by $30 \%$ of consumers at their initial stage of car buying process. Smartphones are emerging as the most used device in car purchase journey as more than $60 \%$ of the customers are investigating about cars their models, features and reviews through their mobiles. Car buyers are paying attention to what is being said about the vehicle they intend to purchase over social media as more than $70 \%$ of car buyers read online reviews before making a purchase decision. $38 \%$ of the customers also refer to social media platforms such as Facebook, LinkedIn, etc. whereas $64 \%$ car buyers watch YouTube videos during their car buying journey. The study further elaborates that consumers have also embraced automation in automobile at retail level wherein they easily interact with the chat-bots of the dealerships, sending and responding to the emails for solving queries and downloading the mobile apps to name the most popular.

Study conducted by Bains and Facebook India in the year 2020 reveals that digital media has reshaped the Indian automobile industry wherein digital sources have replaced traditional sources of communication and helping car buyers search, evaluate, compare and select the vehicles. The research validates that consumers refer to online information such as ratings, reviews and feedback about vehicles even in the showroom. Except the variant of the vehicle, all other aspects namely the fuel type, brand, model, mode of transmission, colour, etc. are decided online. The study indicates that $70 \%$ consumers are already convinced about the brand and 50\% about the model before entering the dealership. The study while acknowledging the role of social media in car buying decisions asserts that social media accounts for more than $40 \%$ of auto sales (Kumar, 2020).

Another study by Digital Marketing Institute (2020) indicates that $95 \%$ of car purchasers rely on digital mode of information. The study further elaborates that $65 \%$ of buyers decide about the car brand to be purchased within 20 days. Online search of car provides abundant information about the variants of car their reviews to the interested group and helps them taking an informed decision. The study validates that with the help of digital channels car buyers decide about the brand to be purchased even before visiting the showroom. Out of different online modes of information YouTube video research mode is most popular and highly acceptable by the car buyers wherein car buyers resort to videos of various car brands to get comprehensive information about models, mileage, price, features of the alternatives available in the market. The study indicates that as many as $70 \%$ car buyers get influenced from the YouTube videos. Social media platforms like Instagram, Twitter and YouTube pave the way for automotive companies to identify the potential buyers on the basis of their search history.

\section{Discriminant analysis application}


SAJM

2,1

56

Study conducted by a very popular third party automobile website "Cardekho.com" attributes digital thrust the most important change affecting car purchase decisions. The study revealed that vast majority $(75 \%)$ of Indian car buyers conduct online research before buying a particular car brand. Mobile phone is the most contemporary digital channel used in car buying decision process (Goyal, 2016). Another study conducted by Ernst and Young (2016) in India revealed that websites was the most used digital channel and mobile phones the most used digital device used by the car buyers. The report presented an optimistic picture of digital landscape in India and stressed that digital marketing in India will grow in years to come an account of young educated digital natives.

Existing literature acknowledges and appreciates the fact that digital channels are dominating the car buyers' purchase journey and marketers using them adequately too. However, existing literature does not have much to offer if one wishes to know for which particular reason a specific digital channel is used. One of the most prominent research gap observed in existing literature is the restricted knowledge of marketers regarding the specific reason(s) accounting for the usage of a particular digital channel of communication. This study aims to fulfil this gap by conducting an empirical study. The results of the study would enable marketers to implement a cost-effective communication process along with facilitating appropriate advertising budget to the selected channel.

\section{Research problem}

All the important stakeholders in Indian automobile industry, i.e. manufacturers, dealers, consumers, suppliers, general public acknowledge the fact that digital interventions have significantly affected the traditional car buying process. Available studies also accept the fact that consumers make use of different digital channels and platforms while buying a car. Marketers spend considerable amount of money to the digital platforms. However, still restricted information is available in marketing domain about specific usage of digital channels while buying a high value items like car. "Digital channels" have been used as an umbrella term abundantly by the researchers and practitioners for all possible digital platforms and medium. This practice is very evident in prominent researches despite the fact that consumers explicitly exhibit their preference for certain digital channels and use few channels more than the others. Efficiency and effectiveness of marketers' communication program can be enhanced if they have knowledge about the particular reason accounting for the usage of the particular channels.

\section{Research objective and methodology}

The study acknowledges the fact that different consumers use different digital channels throughout their car buying decision process. The study wishes to offer more insights into the decision-making process of Indian car buyers by divulging the specific reasons accounting for usage of different digital channels while buying a car. The study also wishes to comprehend the most used digital channel of communication while buying a car. In order to achieve the objectives of the study, a quantitative study was conducted in Delhi using survey methodology. Area wise proportionate sampling was used to collect data from 603 car buyers using at last one digital channel of communication. Census 2011, Government of India was used as frame of reference. Structure questionnaire constructed using interval and nominal scale was used to collect the data. Online mode was used to administer the questionnaire wherein the questionnaire was sent to 2,500 respondents. 639 questions were obtained during the survey period, i.e. November 2019 to March 2020. After data cleaning, 603 responses were considered in the study. Website, social networking sites, smartphones, YouTube, digital TV, digital outdoors, emails, online communities were the major digital channels considered for 
the study. Discriminant analysis was applied as test of significance to arrive at conclusion. The most common reasons accounting for usage of digital channels were identified using the available literature and used as predictors, discriminating or independent variables and usage of each digital channel was used as dependent variable. Data was analysed using SPSS software version 23.

\section{Sample statistics}

$45 \%$ of the sample was represented by the respondents below 35 years of the age. $50 \%$ of the respondents possessed graduate degree, whereas $28 \%$ claimed having post-graduate qualifications. $20 \%$ of the sample was represented by students, whereas $45 \%$ sample was represented by the respondents in service class. Business class constituted $20 \%$ of the sample. 58\% sample was represented by male respondents, whereas female respondents accounted for $42 \%$ of the sample. $38 \%$ respondents belonged to less than 5 lacs per annum income category, whereas $22 \%$ respondents represented the income category of 6-10 lacs per annum.

\section{Most used digital channel}

The results of the study revealed that website was the most used channel of communication while buying a car as $93 \%$ of the car buyers accepted using the same as information source followed by smartphones (used by $80 \%$ ) and YouTube used by $75 \%$ of car buyers (Figure 1). Online communities were used by $70 \%$ of the respondents. Social networking sites as information source were used by $68 \%$ of the car buyers. Feature phones were used the least by the car buyers as only $17 \%$ car buyers accepted using them. Digital outdoors and digital TV were used $45 \%$ and $42 \%$ of the car buyers respectively.

\section{Reason(s) for using particular digital channel}

The study used ten digital channels of communication and aimed to know the particular reason(s) for using specify digital channel. Discriminant analysis was used as test of significance wherein characteristics of digital media such as being informative, interactive, quick, relevant, compatible, facilitating comparison and availability of reviews were taken as predictor or discriminating characteristics and usage, i.e. use and no use; was taken as dependent variable. Predictor or independent variables were measured using interval scale (5 points scale), whereas dependent variable was measured using categorical scale. This section gives the details of the analysis conducted for each communication channel.

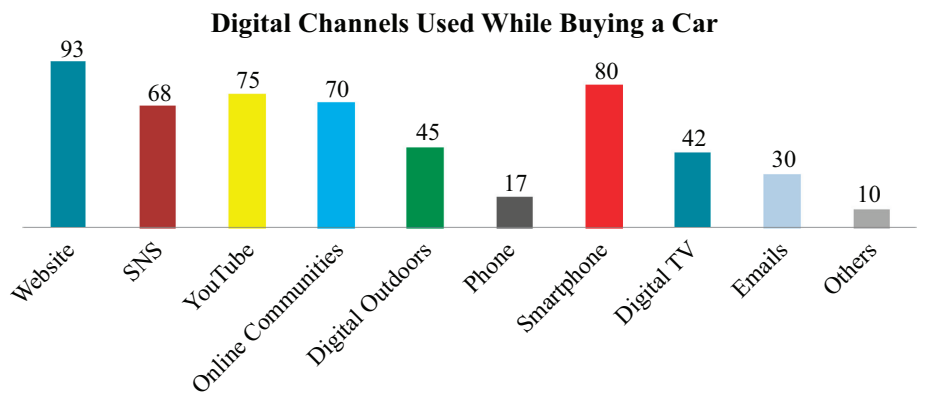

Source(s): Author's Analysis
Discriminant analysis application

(1) 
SAJM

2,1

\section{8}

Table 2.

Group statistics for websites
Websites: compatible, informative and easy to use

Websites, one of the most used digital channels of communication was evaluated to understand the characteristics assuring its use as a digital channel of communication while buying a car. The group statistics (Table 2) showed that there was a difference in mean values assigned by the users and non-users of websites with respect to the characteristics of digital marketing communication. This can be seen from Table 1 that respondents who used websites while buying a car, rated digital marketing communication's characteristics differently (i.e. higher) from the non-user group. However, it can be seen that different characteristics of digital marketing communication for websites have been rated similarly by the users. The same can be understood by analysing the general perception of users wherein word websites results in collective imagery of various digital channels in consumers mind such as social networking sites, online communities, YouTube; rather than simply considering website a digital channel of car marketers' only.

The basic principle in discriminant function is to maximize the variance between the groups in relation to variance within the group, the ratio of which is represented by the "Eigen value". A higher Eigen value is always desirable. Table 3 gives the Eigen values for websites.

Table 3 indicates that Eigen value for the website's discriminant function was found as 0.725. The Eigen value for the function indicated the probability that users and non-users of website differed significantly for various characteristics of digital communication. The table also gives the value of "canonical correlation" which is the simple correlation between discriminant score and their corresponding group memberships (users and non-users). The value of canonical correlation was 0.799 and square of this value was 0.638 which meant that

\begin{tabular}{|c|c|c|c|c|}
\hline \multicolumn{2}{|c|}{ Digital marketing communication characteristics } & \multirow{2}{*}{$\frac{\text { Mean }}{3.23}$} & \multirow{2}{*}{$\frac{\text { Std. Deviation }}{0.971}$} & \multirow{2}{*}{$\frac{\text { Valid } N \text { list wise }}{76}$} \\
\hline No use of Website & Informative & & & \\
\hline & Quick & 3.12 & 1.140 & 76 \\
\hline & Interactive & 3.22 & 1.016 & 76 \\
\hline & Relevant & 2.70 & 1.155 & 76 \\
\hline & Easy to Use & 2.51 & 1.205 & 76 \\
\hline & Availability of Expert Advice & 3.02 & 1.107 & 76 \\
\hline & Easy Comparison & 3.08 & 1.028 & 76 \\
\hline & Availability of Customer Reviews & 3.74 & 1.012 & 76 \\
\hline & Compatibility & 2.51 & 1.137 & 76 \\
\hline \multirow[t]{9}{*}{ Use of Website } & Informative & 3.89 & 0.973 & 527 \\
\hline & Quick & 3.95 & 0.967 & 527 \\
\hline & Interactive & 3.83 & 0.906 & 527 \\
\hline & Relevant & 3.83 & 0.905 & 527 \\
\hline & Easy to Use & 3.53 & 1.088 & 527 \\
\hline & Availability of Expert Advice & 3.74 & 0.920 & 527 \\
\hline & Easy Comparison & 4.05 & 0.922 & 527 \\
\hline & Availability of Customer Reviews & 3.87 & 0.913 & 527 \\
\hline & Compatibility & 3.82 & 0.889 & 527 \\
\hline
\end{tabular}

Source(s): Author's analysis

\begin{tabular}{|c|c|c|c|c|}
\hline Function & Eigen value & $\%$ of variance & Cumulative $\%$ & Canonical correlation \\
\hline dimension 0 & $0.725^{\mathrm{a}}$ & 100.0 & 100.0 & 0.799 \\
\hline
\end{tabular}

Table 3. Eigen values for websites 
about $64 \%$ of variance in discriminating model between users and non-users was due to characteristics of digital marketing communication. In other words, the various characteristics of digital communication successfully accounted for the usage of "website" as a channel of communication while buying a car.

It was also proposed to see for which of the characteristics, a significant difference existed between the users and non-users of website. A one-way ANOVA was carried out for each characteristic of digital marketing communication. Hypothesis for equality of group means was tested with the help of "Wilk's Lambda". Table 4 represents the tests of equality of group means for websites.

This can be seen from Table 4 that Wilk's Lambda was found significant for each characteristic with a significance value of less than 0.05 . The significant results illustrated that for all the characteristics of digital marketing communication, means of both the groups were significantly different from each other. Pooled within-groups matrix was analysed in order to detect the potential problem of multicollinearity. Table 5 provides the correlation matrix between all the predictor variables.

It can be seen from Table 5 that correlation between any pair of variable did not exceed the cut off value of 0.75 , which illustrated that there was not a problem of multicollinearity and discriminant model can be relied upon (Poulsen and French, 2008; Chawla and Sondhi, 2011).

Discriminant analysis also assumes the equality of covariance, i.e. homogeneity across the groups. Box's $M$ statistic tests the assumption of equality of covariance whereby an insignificant result (associated with a $p$ value of more than 0.001 ) indicates the equality of covariance (Grande, 2016). Box's $M$ statistic was found associated with 43.728 with a significance value of 0.059 , which illustrated the homogeneity of covariance between the groups.

\begin{tabular}{lccccc}
\hline Digital marketing communication characteristics (DMCC) & Wilks' lambda & $F$ & df1 & df2 & Sig \\
\hline Informative (I) & 0.983 & 5.127 & 1 & 600 & 0.018 \\
Quick (Q) & 0.992 & 4.301 & 1 & 600 & 0.050 \\
Interactive (Int) & 0.989 & 4.328 & 1 & 600 & 0.038 \\
Relevant (R) & 0.990 & 4.338 & 1 & 600 & 0.041 \\
Easy to Use (ETU) & 0.908 & 7.013 & 1 & 600 & 0.006 \\
Availability of Expert Advice (EA) & 0.987 & 4.959 & 1 & 600 & 0.028 \\
Easy Comparison (EC) & 0.986 & 5.582 & 1 & 600 & 0.025 \\
Availability of Customer Reviews (ACR) & 0.988 & 4.773 & 1 & 600 & 0.030 \\
Compatibility (C) & 0.980 & 7.487 & 1 & 600 & 0.010
\end{tabular}

Discriminant analysis application
Table 4

Tests of equality of group means for websites

\begin{tabular}{|c|c|c|c|c|c|c|c|c|c|c|}
\hline $\mathrm{DMCC}$ & $I$ & $Q$ & Int & $\mathrm{R}$ & ETU & EA & $\mathrm{EC}$ & $\mathrm{ACR}$ & C & \\
\hline I & 1.000 & & & & & & & & & \\
\hline Q & 0.363 & 1.000 & & & & & & & & \\
\hline Int & 0.389 & 0.310 & 1.000 & & & & & & & \\
\hline$R$ & 0.321 & 0.361 & 0.434 & 1.000 & & & & & & \\
\hline ETU & 0.264 & 0.265 & 0.150 & 0.241 & 1.000 & & & & & \\
\hline EA & 0.412 & 0.305 & 0.269 & 0.335 & 0.163 & 1.000 & & & & \\
\hline $\mathrm{EC}$ & 0.432 & 0.401 & 0.333 & 0.349 & 0.164 & 0.390 & 1.000 & & & \\
\hline $\mathrm{ACR}$ & 0.313 & 0.251 & 0.185 & 0.258 & 0.171 & 0.381 & 0.296 & 1.000 & & \\
\hline C & 0.222 & 0.219 & 0.184 & 0.200 & 0.087 & 0.195 & 0.251 & 0.134 & 1.000 & Pooled within-groups \\
\hline \multicolumn{10}{|c|}{ Source(s): Author's analysis } & matrix \\
\hline
\end{tabular}


SAJM

2,1

\section{0}

The estimated unstandardized discriminating function has been given in Table 6. As the scores are unstandardized; the scores in original unit of measurement should be used.

On the basis of information given in Table 6, the discriminant function for usage of website can be written as Eqn (1):

$$
\begin{aligned}
Y= & -3.882+0.583 * I+0.051 * Q+0.129 * \mathrm{Int}+0.196 * R+0.537 * \mathrm{ETU}+0.282 * \mathrm{EA} \\
& +0.452 * \mathrm{EC}+0.175 * \mathrm{ACR}+0.592 * \mathrm{C}
\end{aligned}
$$

Table 6 also represents the standardized Canonical Function Coefficients are independent of the unit of measurement and are similar to "beta" coefficients in regression. These standardized coefficients are used to rank the predictors and the variable with the maximum value is said to contribute the most towards discrimination. It can be seen from Table 5 that compatibility with $64 \%$ contribution followed by being informative with $57 \%$ contribution and easy to use with $50 \%$ contribution had the maximum capacities to discriminate among users and non-users of websites. The structure matrix coefficient gives another way of interpreting the relative contributions of individual predictor variables. Structural coefficients are the correlations obtained by correlating the discriminant score and each of the independent variable. This can be seen from Table 5 that characteristics of digital marketing communication like compatibility, informative and easy to use contributed the most towards discrimination. The mean score for users and non-users group was found separately, which was known as group centroid. The value of group centroids has been given in Table 7.

This can be seen from Table 7 that group centroid value for website users was 0.060 , whereas for non-user group value was -0.414 . These values can be used as decision criteria to classify a respondent into a user or non-user. If the numbers of respondents in both the

\begin{tabular}{lccc}
\hline $\begin{array}{l}\text { Digital marketing } \\
\text { communication } \\
\text { characteristics }\end{array}$ & $\begin{array}{c}\text { Discriminant function } \\
\text { (unstandardized) }\end{array}$ & $\begin{array}{c}\text { Standardized canonical } \\
\text { function coefficients }\end{array}$ & $\begin{array}{c}\text { Structure matrix } \\
\text { coefficients }\end{array}$ \\
\hline Informative (I) & 0.583 & 0.567 & 0.709 \\
Quick (Q) & 0.051 & 0.027 & 0.612 \\
Interactive (Int) & 0.129 & 0.183 & 0.300 \\
Relevant (R) & 0.196 & 0.137 & 0.295 \\
Easy to Use (ETU) & 0.537 & 0.493 & 0.292 \\
Availability of Expert Advice & 0.282 & 0.077 & 0.279 \\
(EA) & 0.452 & 0.210 & 0.092 \\
Easy Comparison (EC) & 0.175 & 0.062 & 0.043 \\
Availability of Customer & & 0.639 & 0.029 \\
Reviews (ACR) & 0.592 & & \\
Compatibility (C) & -3.882 & & \\
(Constant) & & & -0.414 \\
Source(s): Author's analysis & & & 0.060 \\
& & & \\
\hline Website & & &
\end{tabular}

Table 6.

Canonical discriminant function coefficients (unstandardized)

Table 7.

Functions at group centroids

Source(s): Author's Analysis 
categories are the same, then average of both the groups can be taken as the cut off score. However, in the present study out of 603 respondents, 527 were classified as users whereas 76 were classified as non-users, the cut off score would be calculated using Eqn (2).

$$
C=n 1 Y 1+n 2 Y 2 / n 1+n 2
$$

where $Y 1$ and $Y 2$ are the discriminant score for group 1 (No use) and group 2 (use) and $n 1$ and $n 2$ are the sizes of group 1 and 2. By substituting the values in the formula, the cutoff score for the discriminant function was 0 . So, any respondent having a score more than 0 would be classified as a user, whereas score lesser than 0 would be classified as a non-user.

Significance of the discriminating function should be checked to ensure the reliability of the discrimination observed. This is done with the help of a statistic called Wilk's Lambda. Table 7 details about the Wilk's Lambda Statistic.

Wilk's Lambda is computed as a ratio of within group sum of squares to total sum of squares where dependent variable is discriminant score of individual respondent and independent variable is the category to which respondent belongs. It can take a value ranging between " 0 to 1 ", where 0 implies the perfect discrimination and 1 implies no discrimination at all. A small value of Lambda is always appreciated as it implies that discrimination exists. The statistic should always be found significant (as insignificant value indicates the difference among the groups exists because of sampling error). The significance of Wilk's Lambda is tested with the help of Chi-sqaure. The value of Wilk's Lambda of the discriminant function was found as 0.211 associated with a Chi-square statistic value of 24.617 (Table 8). The Chi-square test statistic was found coupled with a significance value of 0.012 , which was less than 0.05 and ascertained the significance of Wilk's Lambda statistic. So, it was concluded that discriminant function explained the group membership really well. Accuracy of the classification by the discriminant function was judged by using classification matrix displayed in Table 9.

It can be seen from Table 9 that discriminant function correctly classifies the $64.3 \%$ of the respondents of current study. The figure was arrived at by calculating the hit ratio (i.e. ratio of no. of correct predictions/ total number of cases). So, it was concluded from the study that characteristics of digital marketing communication like being compatible, informative and easy to use successfully discriminated the most towards the use of websites, the most

\begin{tabular}{lccccc}
\hline Test of Function(s) & & Wilks' lambda & Chi-square & df & Sig \\
\hline dimension 0 & 1 & 0.211 & 24.617 & 9 & 0.012
\end{tabular}

Source(s): Author's analysis
Discriminant analysis application

\begin{tabular}{llcccc}
\hline Classification results $^{\mathrm{a}}$ & \multicolumn{4}{c}{$\begin{array}{c}\text { Predicted group } \\
\text { membership }\end{array}$} \\
& & Website & No use & Use & Total \\
\hline Original & Count & No use & 47 & 29 & 76 \\
& $\%$ & Use & 196 & 341 & 527 \\
& & No use & 48.7 & 51.3 & 100.0 \\
& & Use & 39.1 & 60.9 & 100.0
\end{tabular}

Note(s): a. $64.3 \%$ of original grouped cases correctly classified Source(s): Author's Analysis

Table 9.

Classification results for websites 
SAJM

2,1

\section{2}

networking sites: informative, relevant and easy to use

Digital marketing communication characteristics successfully discriminated between use and non-use of social networking sites while buying a car. The Wilk's Lambda was found significant with a value of 0.963 ( 0.007 sig. level). Digital marketing characteristics like being informative, relevant, easy to use, offering expert advice and availability of customer reviews successfully discriminated towards the usage social networking sites. The centroid value representing the mean score for use and non-use was found as 0.215 and -0.178 and cutoff score for the discriminant function was found as 0 . The discriminant function towards usage of social networking sites can be written as Eqn (3).

$$
\begin{aligned}
Y= & -4.858+0.592 * I-0.110 * Q-0.444 * \mathrm{Int}+0.621 * R+0.188 * \mathrm{ETU}+0.154 \mathrm{EA} \\
& -0.025 * \mathrm{EC}+0.187 * C+0.121 * \mathrm{ACR}
\end{aligned}
$$

Characteristics of being informative (58\% contribution, 0.001 sig. level), relevant (58\% contribution), easy to use ( $21 \%$ contribution), availability of customer reviews $(17 \%$ contribution) and expert advice (15\% contribution) successfully discriminated towards the use of social networking sites as a digital channel while buying a car. However, characteristics like being interactive, facilitating easy comparison, compatible and quick could not discriminate towards the usage of social networking sites.

\section{YouTube: compatible, informative and relevant}

Digital marketing communication successfully discriminated between the use and non-use of YouTube, the largest video sharing site. The Wilk's Lambda for the discriminant function was found significant with a value of 0.945 (0.000 sig. level). All the characteristics except being quick, interactive and easy to use successfully discriminated towards the use and nonuse of YouTube. The centroid value representing the mean score for use and non-use was found as 0.338 and -0.233 and cut off value was found as 0 . The discriminant function towards usage of YouTube can be written as Eqn (4):

$$
\begin{aligned}
Y= & -5.365+0.505 * I-0.239 * Q-0.143 * \mathrm{Int}+0.526 * R-0.062 * \mathrm{ETYU}+0.232 * \mathrm{EA} \\
& +0.057 * \mathrm{EC}+0.594 * C+0.055^{*} \mathrm{ACR}
\end{aligned}
$$

Characteristics that discriminated towards the likely use of YouTube included being compatible (54\% contribution), informative ( $48 \%$ contribution) and relevant $(49 \%$ contribution). The findings can be appreciated from the fact that the video sharing site gives customers an opportunity to view the vehicle from multiple angles on multiple devices namely desktops, laptops, TV, smartphones and tablets. The video format offers a dynamic experience to the viewers and shows the vehicle in the operational condition. Characteristics 
like expert advice and customers' reviews which help customers selecting the right vehicle for also accounted for the usage of YouTube as a channel of communication while buying a car. However, characteristics like being interactive, quick and easy to use did not contribute towards the use of YouTube as a digital channel.

\section{Smartphones: informative, quick and interactive}

Characteristics of digital marketing communication successfully discriminated between the use and non-use of smartphones. The Wilk's Lambda for the discriminant function was found significant with a value of $0.964(0.010$ sig. level). Characteristics like being informative, interactive, quick and compatibility successfully discriminated towards the likely usage of smartphones as a digital channel. The centroid value representing the mean score for use and non-use was found as 0.224 and -0.166 and cutoff value was found as 0 . The discriminant function towards usage of smartphones can be written as Eqn (5).

$$
\begin{aligned}
Y= & -4.768+0.650 * I+.511 * Q+0.467 * \operatorname{Int}-0.164 * R-0.024 * \mathrm{ETU}-0.376 * \mathrm{EA} \\
& -0.486 * \mathrm{EC}+0.226 * C-0.404 * \mathrm{ACR}
\end{aligned}
$$

The result shows that characteristics like being informative (63\% contribution), quick ( $43 \%$ contribution), interactive ( $41 \%$ contribution) and compatible ( $21 \%$ contribution) discriminated the maximum towards the use of smartphones as a digital channel while buying a car. However, characteristics like being relevant, ease to use, easy comparison and availability of customers reviews and expert advice were not able to discriminate successfully between use and non-use.

\section{Online communities: availability of customers' reviews and expert advice}

Digital marketing characteristics productively discriminated between use and non-use of online communities as a digital channel while buying a car. The Wilk's Lambda for the discriminant function was found significant with a value of $0.863(0.007$ sig. level). Characteristics except being quick accounted for the likely usage of online communities as a digital channel while buying a car. The centroid value representing the mean score for use and non-use was found as 0.344 and -0.112 and cutoff value was found as 0 . The discriminant function towards usage of online communities can be written as Eq. (6).

$$
\begin{aligned}
Y= & -5.277+0.386 * I-0.377 * Q+0.311 * \mathrm{Int}+0.172 * R+0.036 * \mathrm{ETU}+0.349 * \mathrm{EA} \\
& +0.166 * \mathrm{EC}+0.559 * C+0.460 * \mathrm{ACR}
\end{aligned}
$$

Online communities were found offering customers' reviews ( $42 \%$ contribution) and experts' advice (35\% contribution) which help customers taking an informed decision. Availability of compatible (31\% contribution) and informative content (30\% contribution) along with interactive nature ( $28 \%$ contribution) also accounted for the use of online communities as a channel of communication while buying a car. However, characteristic of being quick could not discriminate towards the usage of online communities.

\section{Digital outdoors: informative}

Digital marketing characteristics successfully discriminated between use and non-use of digital outdoors as a digital channel while buying a car. The Wilk's Lambda for the discriminant function was found significant with a value of $0.971(0.040$ sig. level). Characteristic of being informative successfully discriminated towards the likely usage of digital outdoors while buying a car. The centroid value representing the mean score for use 
SAJM

2,1

64

and non-use was found as 0.268 and -0.112 and cut off value was found as 0 . The discriminant function towards usage of digital outdoors can be written as Eqn (7)

$$
\begin{aligned}
Y= & -3.379+0.491 * I-0.566 * Q-0.271 * \mathrm{Int}-0.435 * R-0.119 * \mathrm{ETU}-0.252 * \mathrm{EA} \\
& -0.264 * \mathrm{EC}-0.566 * C-0.437 * \mathrm{ACR}
\end{aligned}
$$

Only the characteristic of being informative (48\% contribution) discriminated towards the use of digital outdoors while buying a car. However, characteristics like being interactive, easy to use, offering expert advice and customers' reviews and facilitating easy comparison were not able to discriminate towards the usage of digital outdoors as a digital channel.

Digital TV: easy to use and quick

Easy to use was the most important digital marketing communication's trait that successfully discriminated between the use and non-use of digital TV as a digital channel of communication while buying a car. The Wilk's Lambda for the discriminant function was found significant with a value of 0.970 ( 0.030 sig. level). All other characteristics except being easy to use and quick were not able to successfully discriminate between use and non-use of digital TV. The centroid value representing the mean score for use and non-use was found as 0.266 and -0.118 and cut off value was found as 0 . The discriminant function towards usage of digital TV can be written as Eqn (8).

$$
\begin{aligned}
Y= & -1.410-0.358 * I+0.506 * Q-0.038 * \mathrm{Int}-0.518 * R+0.573 * \mathrm{ETU}-0.206 * \mathrm{EA} \\
& -0.542 * \mathrm{EC}-0.177 * C-0.052 * \mathrm{ACR}
\end{aligned}
$$

Characteristics of being easy to use (63\% contribution) and quick (50\% contribution) discriminated the most towards the use of digital TV as a channel of communication while buying a car. All other characteristics were not able to discriminate towards the usage of digital TV as a digital channel.

\section{Emails: informative and relevant}

Being informative and relevant were the most important digital communication's characteristics that successfully discriminated for the likely usage of emails as digital channel of communication while buying a car. The Wilk's Lambda for the discriminant function was found significant with a value of 0.872 ( $0.010 \mathrm{sig}$. level). All other characteristics except being informative and relevant were not able to successfully discriminate towards usage of emails as a digital channel. The centroid value representing the mean score for use and non-use was found as 0.491 and -0.058 and cut off value was found as 0.43 . The discriminant function towards usage of emails can be written Eqn (9).

$$
\begin{aligned}
Y= & -1.756+0.623 * I-0.564 * Q-0.557 * \mathrm{Int}+0.534 * R-0.370 * \mathrm{ETU}-0.007 * \mathrm{EA} \\
& -0.397 * \mathrm{EC}-0.154 * C-0.131 * \mathrm{ACR}
\end{aligned}
$$

Characteristics of being informative (60\% contribution) and relevant (51\% contribution) discriminated the most towards the use of e-mails as digital channel of communication. All other characteristics were not able to discriminate towards the usage e-mails as a digital channel.

\section{Phone and other channels of communication}

Digital marketing communication characteristics failed to discriminate between the use and non-use of mobile phones and other channels of communication. The findings can be understood with the fact that smartphones are gradually replacing the feature mobile phones. 
Table 10 summarizes the most common reason(s) for using particular digital channel of communication on the basis of maximum contribution made towards discrimination.

It can be seen from the table that websites and "YouTube" were used for being compatible, whereas channels like social networking sites, smartphones, digital outdoors and e-mails were used for being informative. Online communities were used for offering customers' reviews and experts' reviews. Digital TV was used for being easy to use.

The findings of the study reveal that car buyers are making ample usage of digital channels wherein website is the most used digital channel and smartphones are the most used digital devices used by the car buyers. The results of the study corroborate well the studies conducted by Deloitte study (2020), Ernst and Young (2016) and Goyal (2016). However, it must be understood that it is not essential that a car buyer directly reaches the website of the manufacturer. Car buyers might use search engines to reach the marketer's website, so effective search engine optimization (SEO) strategies should be adopted. Important keywords used in the search engines should be used in the website as well as in the links. Effective SEO would result in placing manufacturer's website a higher rank than others. Consumers can also access third-party comparison websites like "carwale.com", "cardekho.com", "cartrade.com" to name the most popular, so utmost care should be paid to what is being mentioned there about a manufacturer's brand. It becomes extremely important to pay attention to other consumers' reviews over such websites as 'car' being a self-expressive product is being subjected to social approval.

The current study identified the specific reason(s) leading towards the use of particular channel of communication and adds immensely to the available literature. Such information is really scarce in the available literature that considers digital media as the umbrella term for all the digital channels available. Earlier studies conducted by Prahalad and Ramaswamy (2004), Smith (2011), Ryan (2014), Muller et al. (2011), Kirkpatrick (2012) and Klososky (2012) reported the reasons for acceptance of digital media by the consumers, but authors did not reveal the specific characteristic(s) leading towards the use and non-use of particular digital channel.

\section{Implications of the study \\ Practical implications}

The study also offers concrete theoretical contribution by unveiling the distinctive factors resulting in usage of the particular digital channel of communication for extensive problem solving product category like car, which is a relatively under-explored area. The results validate the application of digital marketing in a country like India with numerous digital infrastructural bottlenecks in terms of speed, data privacy and security. Still, car buyers are not only adopting the digital channels while purchasing big-ticket items, but also have the

\begin{tabular}{lll}
\hline Sr. No & Digital channel & Most common reason(s) of use \\
\hline 1 & Websites & Compatible \\
2 & Social Networking Sites & Informative \\
3 & YouTube & Compatible \\
4 & Smartphone & Informative \\
5 & Online Communities & Availability of Customers' Reviews, Expert Advice \\
6 & Digital Outdoors & Informative \\
7 & Digital TV & Easy to Use \\
8 & Emails & Informative
\end{tabular}

Source(s): Author's analysis
Discriminant analysis application 
SAJM

2,1

preference for specific channel of communication owing to their integral capabilities. The results exhibit the evolving mindset of the consumers wherein they are not afraid of experimenting with the contemporary digital technologies in a product category which customarily was known to bank highly upon the conventional marketing practices. This indicates a subtle shift in consumer behaviour wherein consumers have become more empowered and are devoting significant time in conducting research about products and services before buying them. Such understanding strengths and broadens the existing knowledge about consumer behaviour.

\section{Managerial implications}

The study offers several managerial implications too. The findings of the study revealed the four most important characteristics of digital marketing communication namely the compatibility, informative, easy to use and availability of reviews which lead towards the usage of various digital channels while buying a car. The finding is an important managerial contribution as it would guide the marketing manager about the best digital marketing channel mix for advertising appropriation assuring the adequate return on investment. Marketers can also capitalize upon the identified characteristics of different digital channels and effectively use these channels for better customer engagements.

The study revealed that websites and YouTube were used by the car buyers for being compatible in nature. The findings imply that both the channels would only be used when content over these channels is compatible with the devices used by the consumers. Marketers must understand that a car buyer looks for compatible content not only over marketers' website but also over most popular video sharing site. It is recommended to offer marketing content in appealing video formats on video sharing sites while keeping in mind the compatibility with various screens and operating system. Video formats carrying the effective demonstrations or 360 degree virtual demos of the vehicles should be used to stimulate the interest of the customers. So, the results imply that while targeting potential customer, this particular combination must be kept into mind and marketers should improve the compatibility of the corporate websites and YouTube content across multiple channels to give a consistent experience to the customers.

Social Networking Sites, Smartphones, e-mails and Digital outdoors were used by car buyers for being informative in nature. Marketers could use this identified mix to meaningfully communicate with the car buyers especially in search for information stage. Car marketers should also upload the updated content regularly over social networking sites. Marketers are suggested to establish a dialogue rather than monologue over social media. Similarly for smartphones, marketers should design interesting mobile applications and mobile websites to offer the relevant information to the customers. "App" of the company should be made available at popular "apps stores". Marketers however must also be cautious enough to understand that mere possession of smartphones does not guarantee its usage while buying a car, rather the informative content accessed via smartphones determines its usage. Communication made through emails should be informative enough to facilitate the decision-making process of the buyers.

Customers used online communities for the availability of customers and experts reviews. The results have some important implications for the marketers wherein it must be noted that it is not enough to make big claims about their brands, but also substantiate such claims with the help of customer testimonials. So marketers are advised to join the consumers' community and identify the opinion leaders who would influence other customers in their car buying decision process. Marketers should pay attention to the comments of customers about their brand over social media and act quickly to the complaints, suggestions and concerns if any, of the customers. 
Overall results of the study imply that marketers must understand that behaviour of the consumers in digital age is continuously changing and expanding and if marketers wish to stay relevant to these almost "always connected" consumers, they have to be in synchronization with their trends and preferences. Marketers must also understand that less than satisfactory experience on key attributes would result in non-usage of digital channels during the car buying decision-making process, resulting in less than optimal return on digital investment. However, consumer search trends during pandemic reveal that there has been an increase in online searchers and purchases (Moneta and Sinclair, 2020). This presents an excellent opportunity for marketers wherein a little impetus in right direction from marketers might tilt the balance in favour of digital channels and non-users might start give digital channels a try (Hajj et al., 2020). Marketers might share easy and succinct information regarding the usage, compatibility and benefits of digital marketing platforms with the non-users which might motivate them to adopt the latter. Non-users might be demonstrated the usage of various digital channels during the showroom visits.

\section{Conclusion}

The study validates that fact that car buying is no longer a unidirectional process and consumers use different digital channels for specific reasons while buying a car. The most used digital channels of communication while buying a car are websites, smartphones, social networking sites and YouTube. It was found in the study that there are distinguished characteristics such as compatibility, informative, easy to used and availability of reviews that account for the usage of particular digital channels of communication while buying a car. The study found the distinctive characteristics of various digital channels leading towards their usage while buying a car which provide valuable insights for the marketers. The study demonstrates the fact that entire car-buying journey has been transformed into a brand experience process with subtle digital interventions. Car marketers and dealers will have to change their customer outreach strategies as per the evolving mindset of the car buyers if they wish to remain competitive and relevant to "always connected" customers.

\section{References}

Adikesavan, T.A. (2014), Management Information Systems: Best Practices and Applications in Business, Prentice Hall of India, New Delhi.

Alghizzawi, M. (2019), "The role of digital marketing in consumer behavior: a survey", International Journal of Information Technology and Language Studies, Vol. 3 No. 1, pp. 24-31.

Armstrong, A. and Hagel, J. (2000), "The real value of online communities", Knowledge and Communities, Vol. 74 No. 3, pp. 85-95.

Automotive Tech Blog (2019), "5 ways digital transformation impacts car dealerships", available at: https://www.fpt-software.com/how-digital-technologies-can-improve-the-car-buying-experience/.

Bagchi, S. (2013), "Automakers go social to woo the next gen customers", CXOtoday.com, available at: http://www.cxotoday.com/story/automakers-see-a-shift-from-traditional-to-social-mediaengagement/.

Bhattacharya, J. (2015), How triggered emails will help increase holiday sales, Techo, available at: http://tech.co/holiday-sales-triggered-emails-2015-12.

$\mathrm{C}+\mathrm{R}$ Research (2014), "The digital influence: how online research puts auto shoppers in control", available at: http://dealers.cars.com/assets/pdf/auto_marketing_digital_influence_study.pdf.

Capgemini (2015), Capgemini Cars Online 2015 Report Highlights Growing Consumer Demand for a More Personalized Car-Buying Experience, Press Release, available at: https://www.capgemini.

Discriminant analysis application 
SAJM

2,1

68

com/news/ capgemini-cars-online-2015-report-highlights-growing-consumer-demand-for-amore-personalized.

Chaffey, D. (2016), "Email campaign tracking with google analytics", Smart Insights, available at: http://www.smartinsights.com/email-marketing/email-marketing-analytics/email-campaigntracking-with-google-analytics/.

Chaffey, D. (2019), Digital Marketing, Pearson, London.

Chaffey, D. and Smith, P.R. (2017), Digital Marketing Excellence: Planning, Optimizing and Integrating Online Marketing, Taylor and Francis, London and New York.

Charan, A. and Dahiya, R. (2015), "Digital marketing and consumer behaviour: an empirical study in Indian car market with special reference to Delhi and NCR", Anveshak, Vol. 4 No. 2, pp. 60-83.

Chawla, D. and Sondhi, N. (2011), Research Methodology: Concepts and Cases, 1st ed., Vikas Publishing House Private, Noida.

Chen, P.Y., Wu, S.Y. and Yoon, J. (2004), "The impact of online recommendations and consumer feedback on sales", Presented at International Conference on Information and Systems (ICIS), Association for Information Systems, Seattle, 31 December, pp. 711-723, available at: http://aisel. aisnet.org/cgi/viewcontent.cgi?article $=1146 \&$ context $=\mathrm{icis} 2004$.

Cox Automotive (2018), “Car buyer journey 2018”, available at: https://b2b.autotrader.com/oem/wpcontent/uploads/2018/03/2018-Cox-Automotive-Car-Buyer-Journey-Brochure.pdf.

Dahiya, R. (2013), "Digital marketing: say goodbye to Kotler's 4 P'S”, JIMS8M: The Journal of Indian Management and Strategy, Vol. 18 No. 2, pp. 32-36.

Dahiya, R. and Gayatri (2017), "Investigating Indian car buyers' decision to use digital marketing communication: an empirical application of decomposed TPB", Vision, Vol. 21 No. 4, pp. 385-396.

Dahiya, R. and Gayatri (2018), "A research paper on digital marketing communication and consumer buying decision process: an empirical study in the Indian passenger car market", Journal of Global Marketing, Vol. 31 No. 2, pp. 73-95.

Deloitte (2020), "How digital marketing is transforming car buying experience", Small Biz Viewpoints, available at: http://www.smallbizviewpoints.com/2020/06/25/how-digital-marketing-istransforming-car-buying-experience/.

Deloitte Global Automotive Study (2019), "How digital technologies can elevate the car-buying experience", available at: https://www2.deloitte.com/us/en/insights/industry/automotive/digitaltechnologies-transform-car-buying-experience.html.

Digital Marketing Institute (2020), "5 ways digital is transforming the car buying experience", available at: https://digitalmarketinginstitute.com/blog/5-ways-digital-is-transforming-the-carbuying-experience.

Durmaz, Y. and Efendioglu, I.H. (2016), "Travel from traditional marketing to digital marketing", Global Journal of Management and Business Research, Vol. 16 No. 2, pp. 35-40.

Edelman, D. and Heller, J. (2015), How Digital Marketing Operations Can Transform Business, Insights and Publications. McKinsey and Company, available at: http://www.mckinsey.com/insights/ marketing_sales/how_digital_marketing_operations_can_transform_business.

Ernst and Young (2016), "Exclusive: a peek at E\&Y's social media marketing India trends study", ET Brand Equity, available at: http://brandequity.economictimes.indiatimes.com/news/digital/ exclusive-a-peek-at-eys-social-media-marketing-india-trends-study/53837084.

Eze, S.C., Chinedu-Eze, V.C., Okike, C.K. and Bello, A.O. (2020), "Critical factors influencing the adoption of digital marketing devices by service-oriented micro-businesses in Nigeria: a thematic analysis approach", Humanities and Social Sciences Communications, Vol. 7 No. 1, pp. 1-14.

Fera, R.A. (2012), "The 14 most arresting interactive outdoor ads: from vibrating benches to geofencing", available at: http://www.fastcocreate.com/3061896/hefty-taps-john-cena-robschneider-to-reboot-the-hefty-vs-wimpy-campaign. 
Goyal, M. (2016), "Buying a car? Indians are big on online research - find out seven new habits of buyers", The Economic Times, available at: http://economictimes.Indiatimes.com/articleshow/ 54873163.cms?utm_source $=$ contentofinterest\&utm_medium $=$ text\&utm_campaign $=$ cppst.

Grande, T. (2016), "Calculating and interpreting box's $m$ for manova and discriminant function analysis (dfa) in SPSS", available at: https://www.youtube.com/watch?v =VvHdjRKXui8.

Gupta, G. and Vohra, A.V. (2019), "Social media usage intensity: impact assessment on buyers' behavioural traits", FIIB Business Review, Vol. 8 No. 2, pp. 161-171.

Hajj, J., Atwi, I. and Raquib, R. (2020), "Adopting emerging technologies in a post COVID -19 world", Strategy, available at: https:/www.strategyand.pwc.com/m1/en/articles/2020/adoptingemerging-technologies-in-a-post-covid-world.html.

Hanna, R., Rohm, A. and Crittenden, V.L. (2011), "We're all connected: the power of the social media ecosystem”, Business Horizons, Vol. 54 No. 3, pp. 265-273.

Hausman, A. (2014), "Consumer decision-making process and social media", Digitalist, available at: http://www.digitalistmag.com/customer-experience/2014/02/25/consumer-decision-makingprocess-and-social-media-01245119.

IDC (2018), "The digitization of the world from edge to core", available at: https://www.seagate.com/ files/www-content/our-story/trends/files/idc-seagate-dataage-whitepaper.pdf.

Ioanăs, E. and Stoica, I. (2014), "Social media and its impact on consumers' behavior", International Journal of Economic Practices and Theories, Vol. 4 No. 2, pp. 295-303.

Jones, A.T., Malczyk, A. and Beneke, J. (2011), "Internet marketing: a highly practical guide to every aspect of internet marketing [monograph]", available at: https:/open.uct.ac.za/bitstream/.../ Internet_Marketing_textbook.pdf?.

Kannan, P.K. (2017), "Digital marketing: a framework, review and research agenda”, International Journal of Research in Marketing, Vol. 34 No. 1, pp. 22-45.

Kaufman, I. and Horton, C. (2014), Digital Marketing: Integrating Strategy and Tactics with Values, a Guidebook for Executives, Managers, and Students, Routledge, Howick Place, London.

Kaushik, R. (2016), "Digital marketing in Indian context", International Journal of Computational Engineering and Management, Vol. 19 No. 2, pp. 12-17.

Key, T.M. (2017), "Domains of digital marketing channels in the sharing economy", Journal of Marketing Channels, Vol. 24 Nos 1-2, pp. 27-38.

Kirkpatrick, D. (2012), "Digital marketing: be relevant, data-driven and precise [web log post]", available at: http://sherpablog.marketingsherpa.com/online-marketing/precision-data-basedmarketing/.

Klososky, S. (2012), "Social technology: the next Frontier”, Financial Executive, Vol. 28 No. 4, pp. 40-46.

KPMG and Facebook (2018), "Understanding the vehicle-buying journey of the connected consumer", available at: https://en-gb.facebook.com/business/news/insights/understanding-the-autobuying-journey-of-the-connected-consumer.

Kulbyte, T. (2020), “Customer experience statistics you need to know for 2021”, available at: https:// www.superoffice.com/blog/customer-experience-statistics/.

Kumar, P. (2020), "90\% buyers research online before showroom visit: how digital platforms affect car buying decision”, available at: https://www.financialexpress.com/auto/industry/90-buyersresearch-online-before-showroom-visit-how-digital-platforms-affect-car-buying-decision/ 1901974/.

Kusuma, P. (2015), "A study on impact of consumer behaviour pattern on buying decision of small cars in Karnataka", International Journal of Innovative Research in Science, Engineering and Technology, Vol. 4 No. 10, pp. 10167-10177.

Lezmi, A. (2020), "Omni-channel customer service best practices", available at: https://www. superoffice.com/blog/omni-channel-customer-service/.

Discriminant analysis application 
SAJM

2,1

Lund, J. (2020), "How customer experience drives digital transformation", available at: https://www. superoffice.com/blog/digital-transformation/.

MacDonald, S. (2016), "Measuring the effectiveness of email marketing [web log post]", Superoffice, available at: http://www.superoffice.com/blog/measuring-the-effectiveness-of-email-marketing/.

Mahalingam, S. and Ashokkumar, B. (2020), "An overview of digital marketing practices in India", International Journal of Research in Engineering, Science and Management, Vol. 3 No. 9, pp. 66-70.

Manzoor, A. (2010), E-Commerce: An Introduction, Lap Lambert Academic Publishing GmbH, KG, Saarbrucken.

MIT (2013), "Digitally mature firms are $26 \%$ more profitable than their peers", available at: http://ide. mit.edu/news-blog/blog/digitally-mature-firms-are-26-more-profitable-their-peers.

Mogensen, D. (2015), “The 5 auto shopping moments every brand must own [Web log post]", available at: https://www.thinkwithgoogle.com/articles/five-auto-shopping-moments-every-brand-mustown.html.

Moneta, J. and Sinclair, L. (2020), "COVID-19 has accelerated digital adoption — the time to transform is now", Think With Google, available at: https://www.thinkwithgoogle.com/intl/en-gb/future-ofmarketing/digital-transformation /covid-accelerated-digital-adoption/.

Muller, P., Damgaard, M., Litchfield, A., Lewis, M. and Hörnle, J. (2011), Consumer Behaviour in a Digital Environment, European Parliament's Committee, Publication Office, Brussels.

Nagar, A. (2020), "Audi India to reduce print advertising, to double down on digital", available at: https://bestmediainfo.com/2020/05/audi-india-to-reduce-print-advertising-to-double-down-ondigital/.

Nguyen, H.T. (2014), "Factors affecting customer satisfaction and trust in an e-commerce setting: a case study of muachung.vn in Vietnam", AU-GSB e-Journal, Vol. 7 No. 1, pp. 43-52, (June).

Parab, U. (2020), "Trends in digital marketing in India”, International Journal of Advanced Research in Science, Communication and Technology (IJARSCT), Vol. 9 No. 5, pp. 171-174.

Poggi, J. (2012), "What you need to know about interactive TV your digital questions answered", available at: http://adage.com/article/digital/interactive-tv/232996/.

Polanco-Diges, L. and Debasa, F. (2020), "The use of digital marketing strategies in the sharing economy: a literature review", Journal of Spatial and Organizational Dynamics, Vol. 8 No. 3, pp. 217-229.

Poulsen, J. and French, A. (2008), "Discriminant function analysis", available at: https:/pdfs. semanticscholar.org/8e10/85b33d84d7015174e30e3e911272b6e1c2fe.pdf.

Prahalad, C.K. and Ramaswamy, V. (2004a), "Co-creating unique value with customers", Strategy and Leadership, Vol. 32 No. 3, pp. 4-9.

Rekha and Jain, P. (2019), "Consumer management in internet age: a study of Indian car buyers digital communication adoption by applying competing models", FIIB Business Review, Vol. 8 No. 4, pp. 279-291.

Rosetta, S.V. (2014), "Rosetta consulting study shows that customer engagement increases market share and drives revenue growth", available at: https:/www.prnewswire.com/news-releases/ rosetta-consulting-study-shows-that-customer-engagement-increases-market-share-and-drivesrevenue-growth-267184761.html.

Rouse, M. (2009), "Digital television (DTV)", available at: http://whatis.techtarget.com/definition/ digital-television-DTV.

Ryan, D. (2014), The Best Digital Marketing Campaigns in the World II, Kogan Page Publishers, London.

Saura, J.R. (2020), "Using data sciences in digital marketing: framework, methods, and performance metrics", Journal of Innovation and Knowledge, Vol. 6 No. 2, pp. 92-102. 
Sharma, M. (2018), "Vrooming ahead in the digital lane", available at: https://www.financialexpress. com/lifestyle/vrooming-ahead-in-the-digital-lane/1063519/.

Singh, S. (2014), "The impact and adoption of mobile banking in Delhi", International Research Journal of Business and Management, Vol. 1, pp. 19-31.

Smith, K.T. (2011), "Digital marketing strategies that Millennials find appealing, motivating, or just annoying", Journal of Strategic Marketing, Vol. 19 No. 6, pp. 489-499.

Srivatsa, V. (2020), "How automotive brands have taken to digital to drive sale", available at: https:// www.financialexpress.com/brandwagon/how-automotive-brands-have-taken-to-digital-to-drivesale/1966970/.

Stokes, R. (2013), "EMarketing: the essential guide to marketing in a digital world”, Quirk eMarketing, available at: https://www.redandyellow.co.za/wp-content/.../emarketing_textbook_ download.pdf.

Syme, C. (2015), "Social media marketing must be relevant", available at: http://www. digitalbookworld.com/2015/social-media-marketing-must-be-relevant/.

Tewari, S. (2020), "Digital ad spends to cross ₹50,000 crore mark by 2025: Report", available at: https:// www.livemint.com/news/india/digital-ad-spends-to-cross-50-000-crore-mark-by-2025-report11579781295911.html.

V12 (2020), "3 ways the automotive industry can reach mobile-first consumers", available at: https:// v12data.com/blog/3-ways-automotive-industry-can-reach-mobile-first-consumers/.

Wertime, K. and Fenwick, I. (2011), DigiMarketing: The Essential Guide to New Media and Digital Marketing, John Wiley and Sons, Hoboken, New Jersey, NJ.

Wigmore, I. (2013), Definition of Compatibility, Techtarget, available at: http://whatis.techtarget.com/ definition/compatibility.

\section{Further reading}

Deighton, J.A. (1996), “The future of interactive marketing”, Harvard Business Review, Vol. 74 No. 6, pp. $151-160$.

Theodore, R. (2019), "Digital marketing in India and its challenges", Emperor International Journal of Finance and Management Research, Vol. 5 No. 1, pp. 1-5.

\section{Corresponding author}

Dimpy Sachar can be contacted at: dimpysachar81@gmail.com

For instructions on how to order reprints of this article, please visit our website:

www.emeraldgrouppublishing.com/licensing/reprints.htm

Or contact us for further details: permissions@emeraldinsight.com 